CANTUA. 2017; 16:1-6

Fecha de recepción: 24.11.2016

Fecha de aceptación: 29.10.2017

\title{
Staphylococcus aureus resistentes a antibioticos aislados de carnes secas
}

\section{Staphylococcus aureus resistant to antibiotics isolated from dry meat}

\section{Isaura V. Ampuero-Aparicio ${ }^{1}$, Heldy Y. Espinoza-Carrasco ${ }^{1}$}

${ }^{1}$ Universidad Nacional San Antonio Abad del Cusco. Cusco, Perú,

${ }^{a}$ Orcid ID: 0000-0002-2310-1213, ${ }^{\mathrm{b}}$ Orcid ID:0000-0002-4016-8815

\section{RESUMEN}

El charqui y chalona son carnes secas de alpaca, cordero o res, obtenidas por procesos de deshidratación, en algunos casos el inconveniente es que sus procesos de obtención presentan carencias de salubridad, estas carnes secas tienen una alta demanda de consumo en nuestra región. El objetivo de este estudio fue determinar Staphylococcus aureus resistente a 08 antimicrobianos de carnes secas (charqui, chalona) de diferentes mercados de abasto de la ciudad del Cusco. Se procesaron un total de 31 muestras donde se aislaron cepas de Staphylococcus aureus. La metodología utilizada fue de la concentración mínima inhibitoria (CMI) mediante la técnica de dilución seriada en placas. Resultados: De las 31 muestra evaluadas se aislaron $51.61 \%$ de Staphylococcus aureus, de los cuales el 90,8\% presentaron resistencia a la eritromicina, $87,7 \%$ a claritromicina, y 100\% de las cepas fueron sensibles a la vancomicina, el 87,7\% a gentamicina, $69,2 \%$ al cloranfenicol y $46,2 \%$ a tetraciclina. Concluyendo que la susceptibilidad antimicrobiana para cepas de Staphyloccocus aureus se observó que el 100\% es resistente a la penicilina y ampicilina, mientas que para vancomicina se obtuvo un $100 \%$ de cepas sensibles.

Palabras clave: carne seca, concentración mínima inhibitoria, resistencia antimicrobiana, Staphylococcus aureus.

\section{ABSTRACT}

The jerky and chalona are dried meats of alpaca, lamb or beef, obtained by dehydration processes, in some cases the drawback is that their obtaining processes present health deficiencies, these dry meats have a high consumption demand in our region. The objective of this study was to determine Staphylococcus aureus resistant to 08 antimicrobials from dried meats (jerky, chalona) from different supply markets in the city of Cusco. A total of 31 samples were processed where 
Staphylococcus aureus strains were isolated. The methodology used was the minimum inhibitory concentration (MIC) using the serial dilution technique on plates. Results: Of the 31 samples evaluated, $51.61 \%$ of Staphylococcus aureus were isolated, of which $90.8 \%$ presented resistance to erythromycin, $87.7 \%$ to clarithromycin, and $100 \%$ of the strains were sensitive to vancomycin, $87.7 \%$ to gentamicin, $69.2 \%$ to chloramphenicol and $46.2 \%$ to tetracycline. Concluding that the antimicrobial susceptibility for Staphyloccocus aureus strains, it was observed that $100 \%$ is resistant to penicillin and ampicillin, while $100 \%$ of susceptible strains were obtained for vancomycin.

Keywords: antimicrobial resistance, dry meat, minimum inhibitory concentration, Staphylococcus aureus.

\section{INTRODUCCIÓN}

El principal problema en la elaboración de carnes secas es la calidad sanitaria de la materia prima, en el Perú más del 90\% de las alpacas no se sacrifican en mataderos autorizados, lo que ocasiona que este alimento se contamine y así convertirse en transmisores de enfermedades. (Hack, 2001 citado en Salvá B, 2009) En nuestra región se consume regularmente carne seca salada, obtenida por procesos de deshidratado, en muchos casos los procesos de beneficio, elaboración, transporte y comercialización, no cumplen con las normas sanitarias. El charqui de alpaca ha demostrado, que es un producto alimenticio de alto valor proteico, que presenta una baja actividad del agua (aw) que lo hace microbiológicamente estable (Salvá, 2009), donde se inhibe el crecimiento de la mayoría de las bacterias en los alimentos. Pero no así a las bacterias halotolerantes como los Staphylococcus aureus.

Los principales mercados de abasto de mayor concurrencia de la ciudad del Cusco, (Vinocanchon, Wanchaq, San Pedro y Ttio), expenden carnes secas (charqui, chalona) en condiciones insalubres que son expuestos a la contaminación ambiental. Según la Norma Sanitaria RM 591-2008/MINSA vigente en nuestro país, solicita evaluar la presencia de diversos microorganismos patógenos como Staphylococcus aureus. Se obtuvieron 31 muestras de carne seca. El propósito de esta investigación fue, aislar e identificar Staphylococcus aureus coagulasa (+), realizar la prueba de concentración mínima inhibitoria (CMI) mediante la técnica de dilución seriada en placas con 08 diferentes antimicrobianos.

\section{MATERIAL Y METODOS}

Se recolectaron muestras de carnes secas del mercado San Pedro, Wanchaq, Ttio y Vinocanchon. Estas fueron recolectadas, de acuerdo a los criterios microbiológicos según la Norma Sanitaria RM-591-/MINSA, Se procesaron en el Laboratorio de Microbiología de los Alimentos de la Universidad Nacional de San Antonio Abad del Cusco. 
Se aislaron e identificaron cepas de Staphylococcus aureus cuagulasa (+), para lo cual se utilizaron diluciones decimales, en condiciones asépticas se pesaron 10gr de cada muestra en un matraz Erlenmeyer, adicionando 90ml de agua peptonada, siguiendo la técnica de dilución se pasa $1 \mathrm{ml}$ del matraz a los tubos de ensayo que contienen $9 \mathrm{ml}$ de agua peptonada, posteriormente se procedió a la siembra de 0,1 $\mathrm{ml}$ de la muestra en agar Baird Parker por agotamiento de superficie, se incubó por $30-48$ horas a $35-37^{\circ} \mathrm{C}$. Seleccionar las cajas que contengan entre 20 a 200 colonias y contarlas colonias características (negras, lustrosas, convexas, rodeadas de un halo claro dentro de anillos opacos). Una vez contadas estas colonias en las placas elegidas se deben hacer pruebas confirmativas, en particular la prueba de la coagulasa, para lo cual se realizó la coloración de gram a varias colonias características, se observó al microscopio cocos grampositivos en racimos, y se sembró en igual número de tubos que contienen infusión cerebro corazón las colonias características y grampositivas, Incubar a $37^{\circ} \mathrm{C}$ por 24 horas, transferir $0,3 \mathrm{ml}$ de cada cultivo a tubos limpios y marcados como prueba de coagulasa que contienen $0,3 \mathrm{ml}$ de plasma fresco humano (o plasma de conejo), incubar a $37{ }^{\circ} \mathrm{C}$ por 4 horas, observar cada hora hasta la formación del coágulo. Si después de este tiempo da negativo, incubar hasta 24 horas, realizar el conteo final sobre la cantidad total de colonias contadas y el número de confirmadas positivas (CLEIBA, 1992). Luego se realizó la determinación de la resistencia a los antibióticos. Se empleó la técnica de dilución en placa (NCCLS, 2002). Se determinaron los porcentajes de susceptibilidad, los patrones de resistencia y los valores de la Concentración Mínima Inhibitoria (CMI). (Cavalieri et al., 2005). Se determinó la CMI por dilución en agar Muller Hilton frente a los siguientes antibióticos: ampicilina (Am), cloranfenicol (C), penicilina (P), eritromicina (Er), gentamicina (Ge), tetraciclina (Te), vancomicina (Va) y claritromicina (CR). La CMI corresponde a la mínima concentración de antibiótico que era capaz de inhibir el desarrollo microbiano de Staphylococcus. aureus.

\section{RESULTADOS}

De las 31 muestras procesadas, 16 muestras presentaron crecimiento de Staphylococcus aureus, que representan el $51.61 \%$ del total (figura 1). De la misma manera según la norma sanitaria RM 591-2008/MINSA, indica que para que un producto sea considerado apto para el consumo humano, solo se acepta como máximo 2 muestras con resultados positivos, con un límite microbiológico de 10 ufc, situación que no se observó en los resultados obtenidos. 


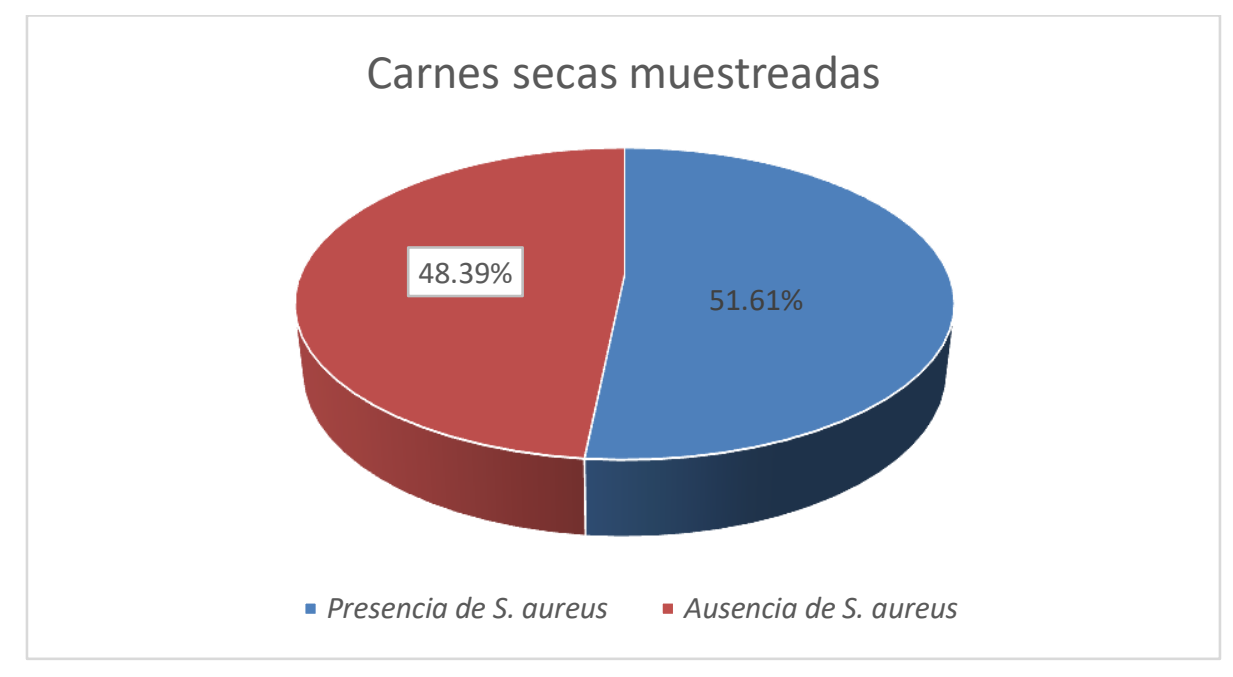

Figura 1. Porcentaje de Staphylococcus aureus aislados en muestras de carnes secas

El $100 \%$ es resistente a la penicilina y ampicilina, $90,8 \%$ a eritromicina, $87,7 \%$ a claritromicina, mientas que para vancomicina se obtuvo un $100 \%$ de cepas sensibles, el $87,7 \%$ a la gentamicina, $69,2 \%$ a cloranfenicol, y $46,2 \%$ a tetraciclina (tabla 1 y figura 2 )

\section{Tabla 1.}

Determinación de la Sensibilidad a antimicrobianos de las cepas de Staphylococcus aureus

\begin{tabular}{|c|c|c|c|c|c|c|}
\hline \multirow[t]{2}{*}{ Antibiotico } & \multicolumn{2}{|c|}{ Sensible } & \multicolumn{2}{|c|}{ Intermedio } & \multicolumn{2}{|c|}{ Resistente } \\
\hline & $\begin{array}{l}\text { Nro } \\
\text { cepas }\end{array}$ & $\begin{array}{c}\text { Porcentaje } \\
\%\end{array}$ & $\begin{array}{l}\text { Nro } \\
\text { cepas }\end{array}$ & $\begin{array}{c}\text { Porcentaje } \\
\%\end{array}$ & $\begin{array}{l}\text { Nro } \\
\text { cepas }\end{array}$ & $\begin{array}{c}\text { Porcentaje } \\
\%\end{array}$ \\
\hline Penicilina & 0 & 0 & 0 & 0 & 65 & 100 \\
\hline Gentamicina & 57 & 87,7 & 0 & 0 & 8 & 12,3 \\
\hline Ampicilina & 0 & 0 & 0 & 0 & 65 & 100 \\
\hline Claritromicina & 2 & 3,1 & 6 & 9,2 & 57 & 87,7 \\
\hline Eritromicina & 0 & 0 & 6 & 9,2 & 59 & 90,8 \\
\hline Cloranfenicol & 45 & 69,2 & 20 & 30,8 & 0 & 0 \\
\hline Vancomicina & 65 & 100 & 0 & 0 & 0 & 0 \\
\hline Tetraciclina & 30 & 46,2 & 14 & 21,5 & 21 & 32,3 \\
\hline
\end{tabular}




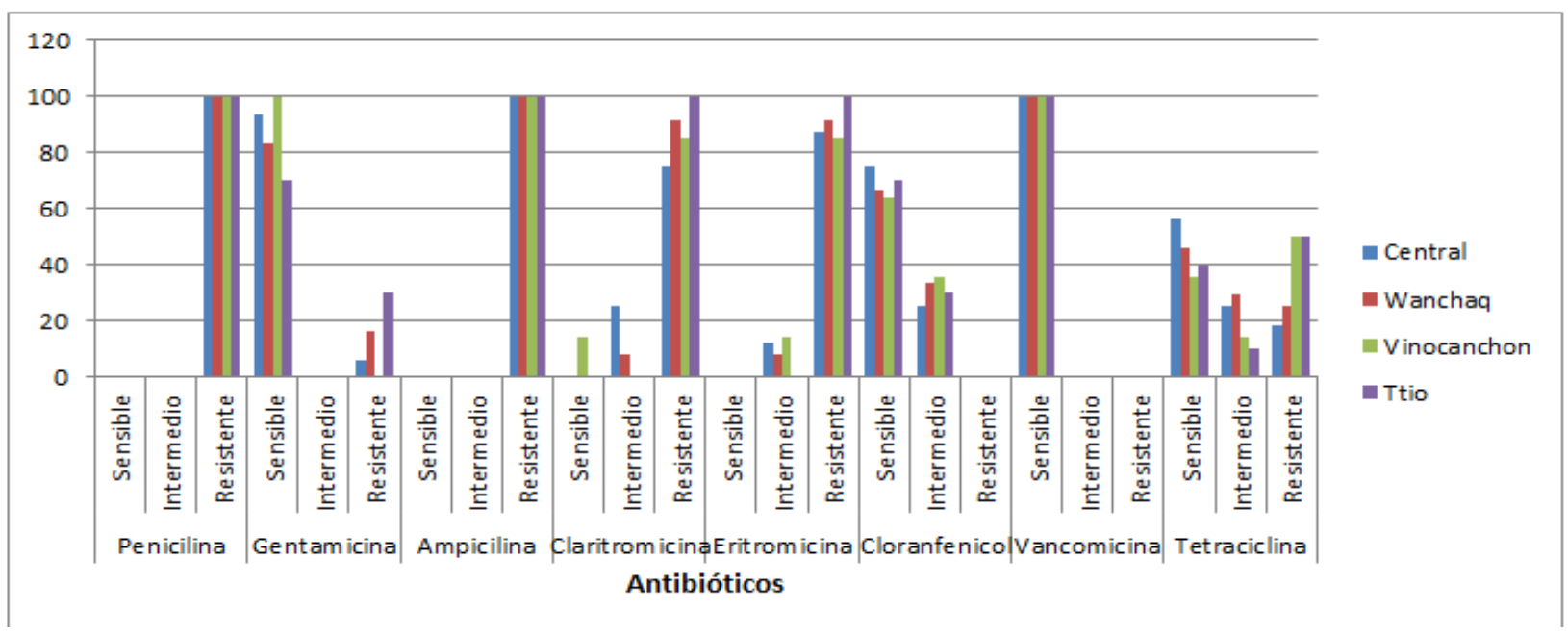

Figura 2. Porcentaje de Sensibilidad, susceptibilidad intermedia y Resistencia de cepas de Staphylococcus aureus

\section{DISCUSIÓN}

Se aislaron bacterias patógenas como Staphylococcus aureus en un 51,61\% de las 31 muestras estudiadas, y las cepas presentaron resistencia a los diferentes antimicrobianos, mostrando que el $100 \%$ es resistente a la penicilina y ampicilina, $90,8 \%$ a eritromicina, $87,7 \%$ a claritromicina, mientas que para vancomicina se obtuvo un $100 \%$ de cepas sensibles, el $87,7 \%$ a la gentamicina, $69,2 \%$ a cloranfenicol, y $46,2 \%$ a tetraciclina. De los resultados mostrados en la (figura 1 ) se puede decir que a diferencia con el trabajo realizado por Lara (2003) donde se evaluó el crecimiento de Staphylococuus aureus en Charqui preparado en condiciones de laboratorio, se demostró que si se sigue las recomendaciones de asepsia y las duras condiciones de procesamiento, el crecimiento de esta bacteria es inhibido, caso que no se observó en los resultados obtenidos. según la investigación realizada por Morales (2005) existen registros que este microorganismo presenta resistencia bastante elevada a penicilina (90\%), eritromicina (35\%), dicloxacilina (10\%-26\%), gentamicina (11\%), tetraciclina (16\%), por su parte la investigación hecha por Gubbay et al., (2003) también reportó resultados de resistencia de las cepas de Staphylococcus aureus a la penicilina en un 94\%. Morales (2005) indica que la resistencia presentada a antibióticos como la penicilina, gentamicina, tetraciclina, ampicilina entre otras, resultaron independientes del origen donde se realizó el aislamiento lo que le hace sugerir que los genes de resistencia están ampliamente difundidos en las cepas de Staphylococcus aureus sin importar si son cepas nosocomiales o comunitarias. 
De acuerdo a los resultados obtenidos en el presente trabajo de investigación, se concluye que el $51.61 \%$ de las muestras de carne seca analizadas de los cuatro mercados de abasto Central, Wanchaq, Vinocanchon y Ttio se aisló Staphylococos aureus, mostrando que el 100\% de capas son resistente a la penicilina y ampicilina, 90,8\% a eritromicina, $87,7 \%$ a claritromicina, mientas el $100 \%$ de cepas fueron sensibles a la vancomicina, el $87,7 \%$ a la gentamicina, $69,2 \%$ a cloranfenicol, y $46,2 \%$ a tetraciclina.

\section{Autor corresponsal:}

Isaura V. Ampuero-Aparicio

Correo electrónico: isaura.ampuero@unsaac.edu.pe

\section{REFERENCIAS}

Cavalieri, S., Rankin, I., Harbeck, R., Sautter, R., Mccarter, Y., Sharp, S., Ortez, J. \& Spiegel, S. (2005). Manual de pruebas de susceptibilidad antimicrobiana II. American Society for Microbiology.

CLEIBA. (1992). Octavo Curso Internacional de Microbiologia e Higiene de los Alimentos. CLEIBA.

Gubbay, L., Galanternik, L., Galan, G., Cabrera, J., Galas, M. \& Degrossi, C. (2003). Sensibilidad antibiótica y detección de enterotoxinas de cepas aisladas de alimentos y manos de manipuladores. Universidad de Belgrano.

Hack, W. (2001). The Peruvian alpaca meat and hide industries - A travel report. Rural Industries Research \& Development Corporation.

Lara, J., Senigalia, B. \& Oliveira, M. (2003). Evaluation of survival of Staphylococcus aureus and Clostridium botulinum in charqui meats. Meat Science, 65(1), 609-613.

Morales, M. \& Ruiz de Chavez, C. (2006).Diferencias en la resistencia a los antimicrobianos de cepas de Staphylococcus aureus obtenidas de diversas fuentes de aislamiento. Revista del Centro de Investigación Universidad La Salle, 7(25).

National Commite for Clinical Laboratory Standard. (2002). Methods for Dilution Antimicrobial Suceptibility test for Bacteria that grow aerobically, Approved Standard- Fifth Edition. National Commite for Clinical Laboratory Standard.

Salvá, B. (2009). Caracterización de la carne y charqui de Alpaca (Vicugna pacos)” [Tesis para optar título de Doctor]. Universidad de León. 